\title{
Therapeutic Potential of Ginger against Renal Injury Induced by Carbon Tetrachloride in Rats
}

\author{
Manal A. Hamed, Sanaa A. Ali, and Nagy Saba El-Rigal \\ Therapeutic Chemistry Department, National Research Center, Dokki 12311, Cairo, Egypt \\ Correspondence should be addressed to Manal A. Hamed, manal_hamed@yahoo.com
}

Received 17 October 2011; Accepted 19 December 2011

Academic Editors: D. M. Lloyd and A. Mentese

Copyright ( $) 2012$ Manal A. Hamed et al. This is an open access article distributed under the Creative Commons Attribution License, which permits unrestricted use, distribution, and reproduction in any medium, provided the original work is properly cited.

\begin{abstract}
The objective of this study was to evaluate the potential of successive ginger extracts (petroleum ether, chloroform, and ethanol) against nephrotoxicity induced by $\mathrm{CCl}_{4}$ in rats. The evaluation was done through measuring kidney antioxidant parameters: glutathione (GSH), lipid peroxides (LPO), and superoxide dismutase (SOD). Renal function test: urea, creatinine and serum protein values, were also evaluated. The work was extended to examine tissue inflammatory mediators, prostaglandin- $\mathrm{E}_{2}\left(\mathrm{PGE}_{2}\right)$, collagen content and the kidney histopathology. Severe alterations in all biomarkers were observed after injury with $\mathrm{CCl}_{4}$. Treatment with ginger extracts resulted in markedly decreased levels of $\mathrm{LPO}, \mathrm{PGE}_{2}$, collagen and kidney function tests, while increased levels of GSH, SOD and serum protein were observed. In conclusion, extracts of ginger, particularly the ethanol, resulted in an attractive candidate for the treatment of nephropathy induced by $\mathrm{CCl}_{4}$ through scavenging free radicals, improved kidney functions, inhibition of inflammatory mediators, and normalizing the kidney histopathological architecture. Further studies are required in order to identify the molecules responsible of the pharmacological activity.
\end{abstract}

\section{Introduction}

$\mathrm{CCl}_{4}$ is a potent, lipid-soluble hepatotoxin that, when bound to lipid and protein, enhances the peroxidative process [1]. Recent studies have demonstrated that $\mathrm{CCl}_{4}$ can cause generation of reactive oxygen species (ROS) in many tissues other than the liver including the kidney, heart, lung, testis, brain, and blood [2]. Free radicals that induce lipid peroxidation cause cell membrane damage leading to a number of pathological changes in acute and chronic renal injuries $[3,4]$. The key enzyme involving $\mathrm{CCl}_{4}$-induced nephrotoxicity is cytochrome P450, which is localized in the cortical tubule cells, and the increased lipid peroxidation is evident in the renal brush border [5]. $\mathrm{CCl}_{4}$ also affects renal mitochondrial function including calcium flux across mitochondrial membranes [5].

Renal fibrosis is the principal process involved in the progression of chronic kidney disease [6], ureteral obstruction, malignant hypertension, severe diabetic condition, or chronic exposure to heavy metals [7]. The development of renal fibrosis involves the progressive appearance of glomerulosclerosis, tubulointerstitial fibrosis, and changes in renal vasculature [6]. At a molecular level, fibrosis can be defined as an excessive accumulation of extracellular matrices such as collagen and fibronectins [6]. The presence of kidney fibrosis seems mostly to be viewed as an endpoint or marker of tissue or organ failure and loss of function [8].

Reports documented that several herbal extracts and plant-derived pure molecules could protect organs against $\mathrm{CCl}_{4}$ by enhancing the antioxidant activity [9]. Endogenous antioxidants in medicinal herbs may play an important role as a defense against oxidative damage and protecting the biological functions of cells [10].

Zingiber officinale Roscoe (Zingiberaceae) is the most widely used spice worldwide. It has been reported as an antioxidant and detoxifying agent against alcohol abuse [11] and bromobenzene intoxication [12]. Islam and Choi [13] and Matsuda et al. [14] evaluated its antidiabetic and antihyperlipidemic activity. In addition, Habib et al. [15] showed its anticancer effect in liver hepatoma. Despite the favorable ethnopharmacological properties of 
ginger, its protective effect against nephrotoxicity by $\mathrm{CCl}_{4}$ has not previously been explored and its role as diminished factor of fibrosis could be a marker of therapeutic benefit.

In the present study, we evaluated the effect of successive extracts of Zingiber officinale rhizome on nephropathy induced by $\mathrm{CCl}_{4}$. The evaluation was carried out through measuring antioxidant parameters, kidney function values, inflammatory mediators, and the histopathological architecture of the kidney.

\section{Material and Methods}

2.1. Chemicals. All chemicals in the present study were of analytical grade, products of Sigma (US), Merck (Germany), and $\mathrm{BDH}$ (England).

2.2. Plant Collection. Zingiber officinale was purchased from a local market (Hyper One Market, 6th October City, Egypt). The plant material was identified by Dr. Manal Shabana, Phytochemistry and Plant Systematic Department, National Research Center, Cairo, Egypt, and voucher specimen (ZOR2010) was deposited as a reference. Dried rhizomes were ground in a grinder with $2 \mathrm{~mm}$ diameter mesh. Five hundred $\mathrm{g}$ of dry powder was kept in tightly closed container until needed.

2.3. Plant Extraction. The dried powered rhizome was sequentially extracted in a Soxhlet (Toshiba, India) apparatus using solvent of increasing polarities: petroleum ether $\left(40-60^{\circ} \mathrm{C}\right)$, chloroform, and $95 \%$ ethanol for $72 \mathrm{~h}$ of each solvent [16]. Solvent removal was carried out under vacuum for drying at $40^{\circ} \mathrm{C}$, producing semisolid residues of $1.3,0.80$, and $2.35 \% \mathrm{w} / \mathrm{w}$, respectively.

2.4. Phytochemical Screening. All extracts were tested for sterols, tannins and terpenes [17], flavonoids [18], carbohydrates, and alkaloids [19].

2.5. Animals. Male Wistar albino rats (100 to $120 \mathrm{~g}$ ) were selected for this study. They were obtained from the Animal House, National Research Center, Egypt. All animals were kept in controlled environment of air and temperature with access of water and diet ad libitum.

2.6. Ethics. Anesthetic procedures and handling with animals complied with the ethical guidelines of Medical Ethical Committee of the National Research Centre in Egypt (approval number: 10031).

2.7. Doses of Administration. Administration regime was twice a week for six consecutive weeks. Five hundred microliters of $\mathrm{CCl}_{4}$ diluted 1:9(v/v) in olive oil was injected intraperitoneally [20]. Ginger extracts $(200 \mathrm{mg} / \mathrm{kg}$ body weight) were administered orally [12]. Silymarin, a reference herbal drug ( $100 \mathrm{mg} / \mathrm{kg}$ body weight), was administered orally [21].
2.8. Experimental Design. 60 male rats were used in this study. Animals were divided into 10 groups (6 rats each). Group 1 served as normal healthy control rats. Groups 25 were normal healthy rats orally administrated different ginger extracts (petroleum ether, chloroform, and ethanol) or silymarin. Group 6 was intraperitoneally injected with $\mathrm{CCl}_{4}$. Groups 7-9 were forced in the same time and for the same duration with $\mathrm{CCl}_{4}$ and different plant extracts. Group 10 was forced with $\mathrm{CCl}_{4}$ and silymarin.

2.9. Sample Preparations. Serum sample: blood was collected from each animal by puncture of sublingual vein in clean and dry test tubes, left 10 minutes at room temperature to clot, and centrifuged at $3000 \mathrm{rpm}$ for serum separation. The separated serum was stored at $-80^{\circ} \mathrm{C}$ for further determinations of kidney function tests and total protein.

Tissue sample: kidney tissue was homogenized in cold $0.9 \mathrm{~N} \mathrm{NaCl}(1: 9 \mathrm{w} / \mathrm{v})$ solution, centrifuged at $3000 \mathrm{rpm}$ for 10 minutes, separated from the supernatant and stored at $-80^{\circ} \mathrm{C}$ for further antioxidant determinations and prostaglandin- $\mathrm{E}_{2}\left(\mathrm{PGE}_{2}\right)$.

2.10. Biochemical Assays. Lipid peroxide (LPO) was determined as malondialdehyde. Its concentration was calculated using the extinction coefficient value $1.56<10^{5} \mathrm{M}^{-1} \mathrm{~cm}^{-1}$ and read at $535 \mathrm{~nm}$ by the method of Buege and Aust [22].

Glutathione (GSH) was assayed using dithiobis-2-nitrobenzoic acid (DTNB) in PBS according to Moron et al. [23]. The color developing reaction was read at $412 \mathrm{~nm}$.

Superoxide dismutase (SOD) was carried out by the method of Nishikimi et al. [24], where the oxidation of $\mathrm{NADH}$ was mediated by superoxide radical and the following increase in absorbance, measured at $560 \mathrm{~nm}$ using the molar extinction coefficient of NADH $\left(6.22 \times 10^{3} \mathrm{M}^{-1} \mathrm{~cm}^{-1}\right)$.

Urea was determined by the method of Tabacco et al. [25], where the conversion of urea in the sample by urease enzyme provided a colored complex that can be measured by spectrophotometry (LKB, Sweden) at $600 \mathrm{~nm}$.

Creatinine was measured by the method of Bartels and Böhmer [26]. Creatinine in the sample reacts with picrates in alkaline medium forming a colored complex at $500 \mathrm{~nm}$.

Serum total protein was assayed according to Bradford [27]. Coomassie Brilliant Blue dye reacts with Bradford reagent to give a blue complex, which is measured colorimetrically at $595 \mathrm{~nm}$.

$\mathrm{PGE}_{2}$ assay is based on the competition between $\mathrm{PGE}_{2}$ and $\mathrm{PGE}_{2}$-acetylcholinesterase conjugate for a limited amount of $\mathrm{PGE}_{2}$ monoclonal antibody. This antibody binds to goat polyclonal anti-mouse IgG attached previously to the well. After acetylcholinesterase substrate was added, a yellow color complex was formed and intensity of absorbance was read at $412 \mathrm{~nm}$ [28].

2.11. Histopathological Study. Kidney tissues were excised from sacrificed animals, individually weighed, and, from them, $5 \mu \mathrm{m}$ thickness slices were cut, fixed in $10 \%$ paraformaldehyde, and embedded in paraffin wax blocks. Tissue 
sections of $5 \mu \mathrm{m}$ thick were stained with haematoxylin and eosin (H\&E) and Masson's trichrome and then examined under light microscope for determination of pathological changes. A minimum of 10 fields for each slide were examined and scored semiquantitatively for severity of changes and collagen deposition. The scoring was done as none $(-)$, mild $(+)$, moderate $(++)$, and severe $(+++)$ changes. Collagen deposition (blue spots) was expressed as normal $( \pm 10 \%)$, mild $(10-25 \%)$, moderate $(26-50 \%)$, and marked $(>56 \%)$ [29].

2.12. Statistical Analysis. All data were expressed as mean \pm $\mathrm{SD}$ of six rats in each group. Statistical analysis was carried out by one-way analysis of variance (ANOVA), Costat Software Computer Program:

$$
\begin{aligned}
\% \text { change } & =\frac{\text { control mean }- \text { treated mean }}{\text { control mean }} \times 100, \\
\% \text { improvement } & =\frac{\text { treated mean }- \text { intoxicated mean }}{\text { control mean }} \times 100 .
\end{aligned}
$$

\section{Results and Discussion}

3.1. Phytochemical Screening. Our previous work by [30] revealed the presence of lipid contents in petroleum ether extract. Chloroform extract contained moderate concentrations of sterols and terpenes. Phytochemical screening of the ethanol extract revealed abundant presence of flavonoids and tannins. High concentration of carbohydrates and moderate concentration of alkaloids were also recorded. These data were in accordance with Anosike et al. [31] who found the same major constituents in ginger ethanol extract. It was clear that the concentrations of the most active compounds were present in ethanol extract.

3.2. Potency of Ginger as Free Radicals Scavenger. Some chemicals cause damage to renal tissue by ROS production. $\mathrm{CCl}_{4}$ is known to induce ROS, deplete antioxidant defenses, and lead to oxidative stress in different tissues. With regard to the enzymatic and nonenzymatic antioxidant levels, the present study revealed significant reduction in glutathione (57.53\%) and superoxide dismutase $(54.04 \%)$ in $\mathrm{CCl}_{4}$-treated rats, while lipid peroxides recorded significant increase $(212.26 \%$, Figure 1). This observation was in accordance with Khan et al. [4] who reported the same disturbance in the antioxidant levels after $\mathrm{CCl}_{4}$ induction of damage. The reduction of glutathione level concerning its role as antioxidant gives an additional support of the elevation of free radicals involved in renal toxicity by $\mathrm{CCl}_{4}$. In addition, reductive dehalogenation of $\mathrm{CCl}_{4}$ by the $\mathrm{P} 450$ enzyme system to the highly reactive trichloromethyl radical initiates the process of lipid peroxidation, which is considered to be the most important mechanism in the pathogenesis of renal damage [3]. Moreover, these metabolites can react with sulfhydryl groups of glutathione and protein thiols to alter the redox status of cells [32]. Therefore, GSH is considered an important defense against lipid oxidative damage in the kidneys eliminating hydrogen peroxide, peroxyl and hydroxyl radicals formed during this process. As SOD is a glutathione-level-dependent enzyme, its activity was decreased by the depletion of glutathione level [33]. Hence, it was identified as a potential urinary marker of $\mathrm{CCl}_{4}$-induced hepatorenal toxicity [34].

Treatment with ethanol extract of ginger recorded improvement of the GSH, LPO, and SOD by 39.72, 184.01, and $40.09 \%$, respectively. Chloroform extract enhanced the antioxidant parameters by $24.65,171.15$, and $33.48 \%$, while petroleum ether showed amelioration with $12.73,150.29$ and $25.67 \%$. It was clear that ethanol extract recorded the highest improvement levels due to its higher concentration of flavonoids, tannins, and alkaloids, the naturally occurring antioxidants. Silymarin as hepatic supportive drug may also play a role in attenuation of free radicals deleterious action on the kidney through stimulation of the antioxidant efficiency by $28.76,115.53$, and $17.19 \%$, respectively. Preventive effects of ginger against $\mathrm{CCl}_{4}$-induced oxidative stress could be attributed to its high level of polyphenol compounds (6-gingerol and its derivatives), which have a high antioxidant activity [35]. These compounds could scavenge the free radicals of $\mathrm{CCl}_{4}$ generated through $\mathrm{P} 450$ enzyme system and thereby diminish the oxidative injuries. Ginger may also impair $\mathrm{CCl}_{4}$-mediated lipid peroxidation through decreased production of free radical derivatives. Administration of ginger extracts to Group 1 animals showed insignificant changes in all the antioxidant parameters confirming the potency of the ginger extracts as anti-freeradicals-producer.

3.3. Effect of Ginger on Renal Disorder Biomarkers. High levels of urea $(44.60 \%)$, creatinine $(43.70 \%)$, and lower level of serum protein $(23.40 \%)$ were recorded in $\mathrm{CCl}_{4}$ group (Figure 2). This was in agreement with Khan et al. [3] who reported that chronic renal injuries by $\mathrm{CCl}_{4}$ intoxication were associated with urea and creatinine elevation and considered as indicators of kidney injury, where the serum creatinine level does not rise until at least half of the kidney nephrons are destroyed. Renal injuries may contribute to low level of serum protein that might have resulted from remarkable leakage into urine due to injuries in glomeruli and tubules [4].

Treatment with different extracts of ginger ameliorated kidney function parameters by $39.52,34.55$, and $21.27 \%$ for ethanol extract and 33.49, 24.35, and $18.08 \%$ for chloroform extract, while petroleum ether showed improvement by $32.86,17.86$, and $12.76 \%$ for urea, creatinine, and serum protein, respectively. Silymarin ameliorated the kidney function markers by $35.24,36.87$, and $19.14 \%$. Some investigators documented that different plant extracts significantly improve renal injuries induced by $\mathrm{CCl}_{4}$ intoxication $[3,36]$. Normal rats treated with ginger extracts recorded significant decrease in urea and creatinine levels as compared to control group (Group 1), which give an additional support to the role of the extracts in eliminating waste products and as antioxidant. This findings were in agreement with Mehrdad et al. [37] who stated that ginger has a beneficial effect for removal of urea and creatinine 


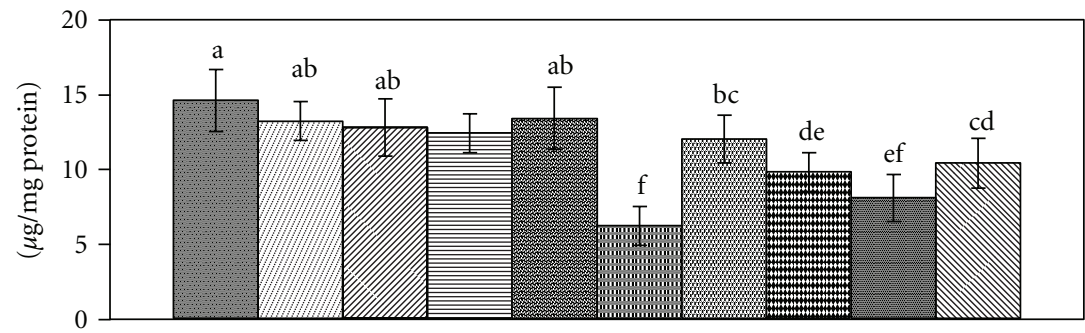

GSH

(a)

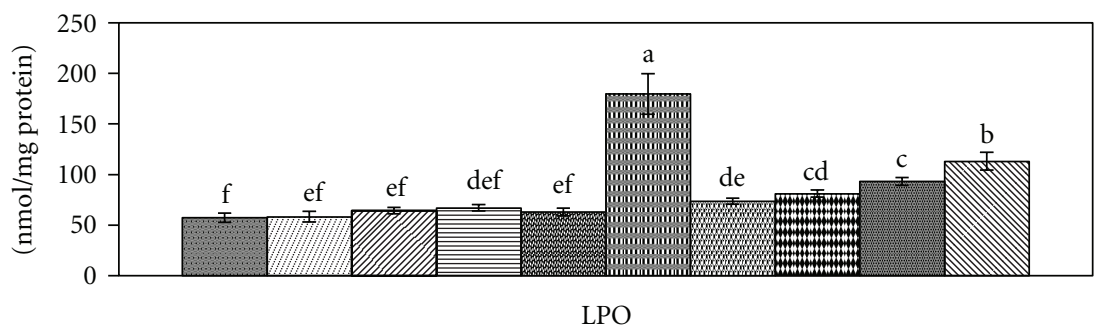

(b)

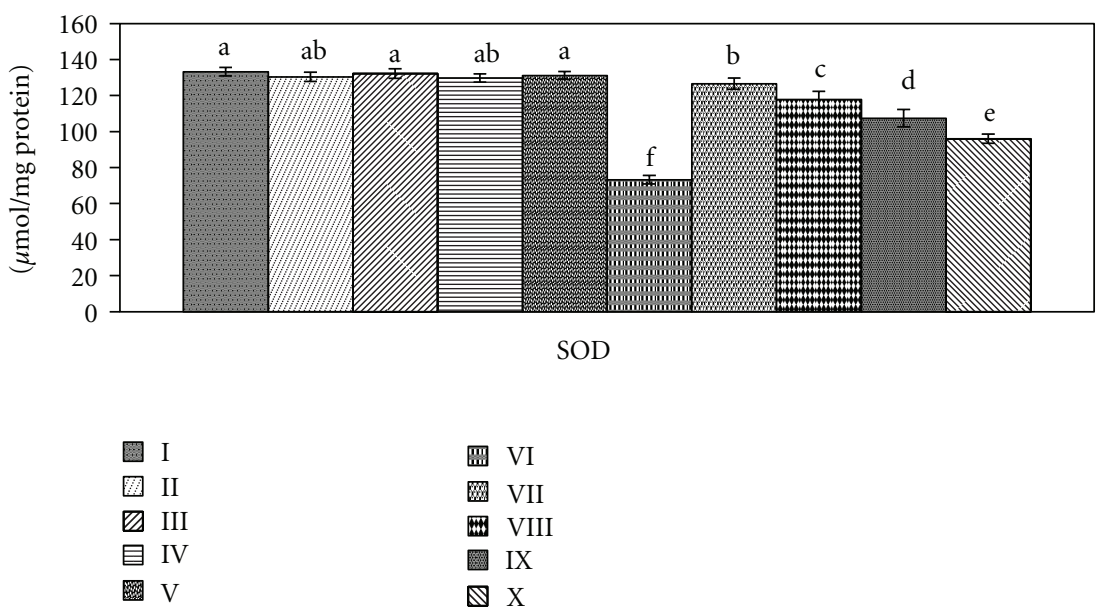

(c)

Figure 1: Effect of Zingiber officinale on antioxidant levels: glutathione (GSH), lipid peroxides (LPO) and superoxide dismutase (SOD). Groups I: control, II: control treated with ethanol extract, III: control treated with chloroform extract, IV: control treated with petroleum ether extract, V: control treated with silymarin, V1: intoxicated with $\mathrm{CCl}_{4}$, VII: intoxicated with $\mathrm{CCl}_{4}$ and treated with ethanol extract, VIII: intoxicated with $\mathrm{CCl}_{4}$ and treated with chloroform extract, IX: intoxicated with $\mathrm{CCl}_{4}$, treated with petroleum ether extract, and X: intoxicated with $\mathrm{CCl}_{4}$ and treated with silymarin. Data are mean $\pm \mathrm{SD}$ of six rats in each group. Statistical analysis is carried out by one-way analysis of variance (ANOVA); Costat Computer Program. Unshared letters are significance values between groups at $P<0.05$.

from plasma of normal mice treated with its alcoholic extract and considered as a therapeutic herb to manage renal function.

3.4. Role of Ginger against Inflammation. In kidney, $\mathrm{PGE}_{2}$ is the main prostaglandin, playing important roles in vasoconstriction, maintaining homeostasis, development of pathological settings, and regulation of salt and water reabsorption. $\mathrm{PGE}_{2}$, as an inflammatory mediator, recorded significant increase $(23.11 \%)$ in kidney tissue of $\mathrm{CCl}_{4}$ treated group (Figure 3). This was in accordance with Choi et al. [38] who recorded $\mathrm{PGE}_{2}$ enhancement after acute nephrotoxicity of melamine, cyanuric acid, and a mixture of them. Carlsen et al. [39] observed severe production of $\mathrm{PGE}_{2}$ in renal medullary interstitial cells when subjected to osmotic, inflammatory, and mechanical stress. Oxidative stress induced by $\mathrm{CCl}_{4}$ can promote renal vasoconstriction [4], which enhanced $\mathrm{PGE}_{2}$ production. Nørregaard et al. [40] 


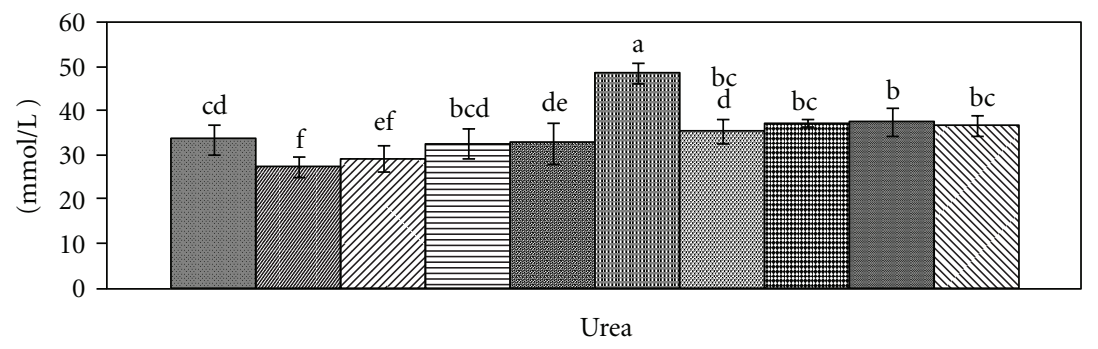

(a)

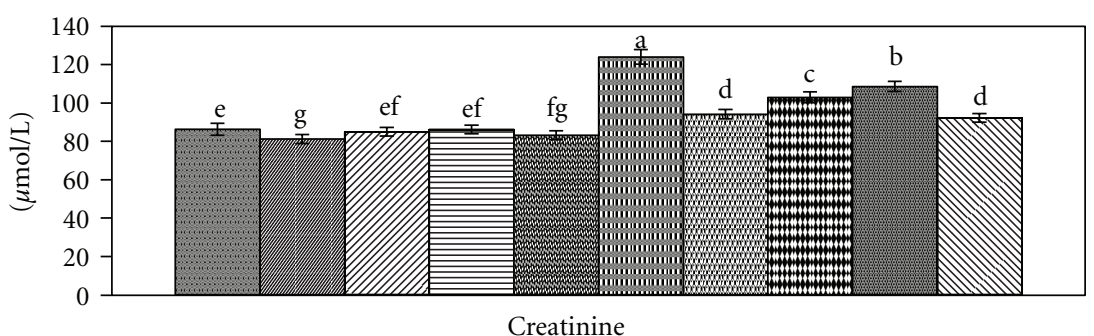

(b)

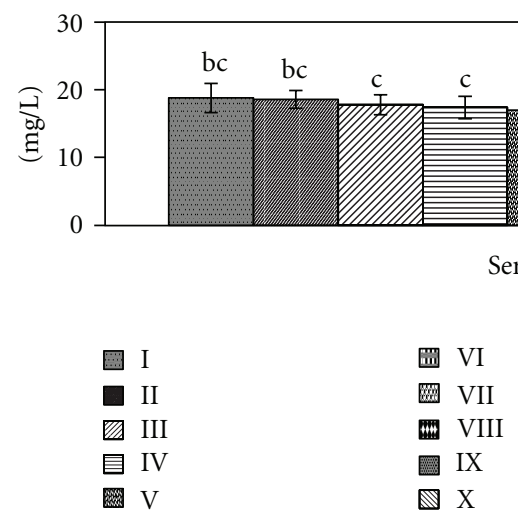

(c)

FIGURE 2: Effect of Zingiber officinale on kidney function parameters: urea, creatinine, and serum protein. Groups I: control, II: control treated with ethanol extract, III: control treated with chloroform extract, IV: control treated with petroleum ether extract, V: control treated with silymarin, V1: intoxicated with $\mathrm{CCl}_{4}$, VII: intoxicated with $\mathrm{CCl}_{4}$ and treated with ethanol extract, VIII: intoxicated with $\mathrm{CCl}_{4}$ and treated with chloroform extract, IX: intoxicated with $\mathrm{CCl}_{4}$ and treated with petroleum ether extract, and X: intoxicated with $\mathrm{CCl}_{4}$ and treated with silymarin. Data are mean \pm SD of six rats in each group. Statistical analysis was carried out by one-way analysis of variance (ANOVA); Costat Computer Program. Unshared letters are significance values between groups at $P<0.05$.

added that bilateral ureteral obstruction promoted accumulation of prostaglandins in cortex and inner medullar tissue of kidney in rats.

Treatment with ginger extracts (ethanol, chloroform, and petroleum ether) improved $\mathrm{PGE}_{2}$ levels by $14.05,6.52$, and $5.75 \%$ respectively, while silymarin recorded $7.70 \%$. This was in accordance with $\mathrm{Hsu}$ et al. [41] who found that Orthosiphon aristatus, used for the treatment of renal inflammation, kidney stones, and dysuria, would act by suppression of the production of lipopolysaccharide-induced nitric oxide and $\mathrm{PGE}_{2}$ by inhibiting ROS generation and reducing the expression of inducible nitric oxide synthase and cyclooxygenase- 2 .

3.5. Efficacy of Ginger against Glomerular Sclerosis. The normal glomerular basement membrane, composed of type IV collagen, has an important function in the process of filtration [42]. Therefore, increased collagen production by mesangial cells plays a key role in the development and progression of glomerular sclerosis [43]. These data were in parallel with our results by the observed glycogen deposition $(60.2 \%$, Figure 3$)$ in kidney after $\mathrm{CCl}_{4}$ induction. Treatment 


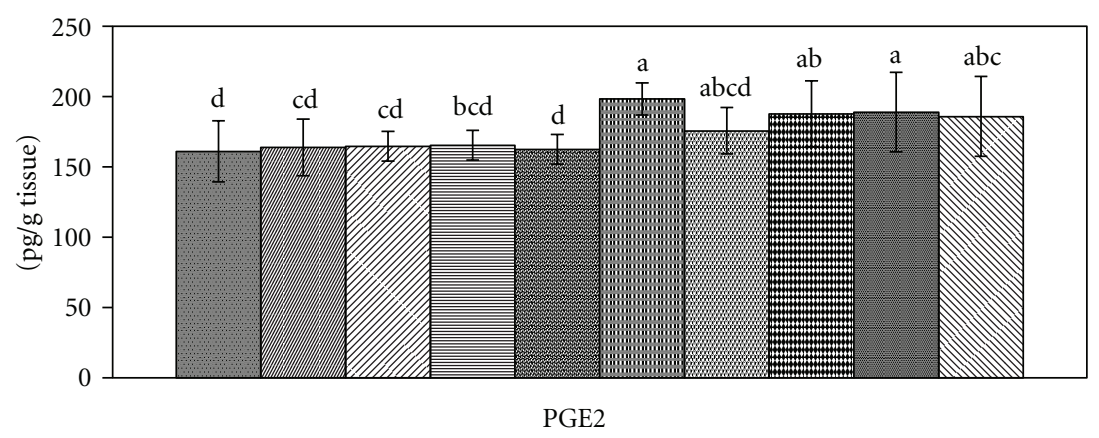

(a)

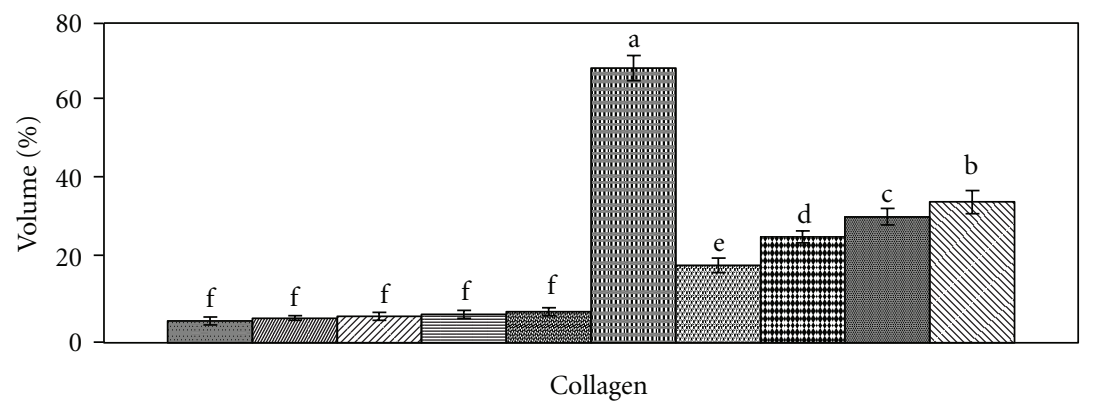

\begin{tabular}{|c|c|}
\hline I & 罭 VI \\
\hline$\square$ II & VII \\
\hline 团 III & VIII \\
\hline 冒 IV & 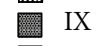 \\
\hline $\mathrm{V}$ & $\nabla x$ \\
\hline
\end{tabular}

(b)

FIGURE 3: Effect of Zingiber officinale on prostaglandin $\mathrm{E}_{2}\left(\mathrm{PGE}_{2}\right)$ and collagen percentage. Groups I: control, II: control treated with ethanol extract, III: control treated with chloroform extract, IV: control treated with petroleum ether extract, V: control treated with silymarin, V1: intoxicated with $\mathrm{CCl}_{4}$, VII: intoxicated with $\mathrm{CCl}_{4}$ and treated with ethanol extract, VIII: intoxicated with $\mathrm{CCl}_{4}$ and treated with chloroform extract, IX: intoxicated with $\mathrm{CCl}_{4}$ and treated with petroleum ether extract, and X: intoxicated with $\mathrm{CCl}_{4}$, treated with silymarin. Data of $\mathrm{PGE}_{2}$ are mean $\pm \mathrm{SD}$ of six rats in each group. Collagen percentages are mean of ten fields of collagen deposition under light microscope $(100 x)$. Statistical analysis is carried out by one-way analysis of variance (ANOVA); Costat Computer Program. Unshared letters are significance values between groups at $P<0.05$.

with different ginger extracts and silymarin recorded collagen deposition by $17,23.2,27.6$, and $30.8 \%$ respectively. Normal rats treated with plant extracts and silymarin showed normal levels of collagen $(5.4,5.8,6.2$, and $6.8 \%$, resp.), revealing a role of the extract as a non inducer of collagen deposition or fibrosis.

3.6. Ginger against Nephropathy Induced by $\mathrm{CCl}_{4}$. Kidney histopathological features of control and control treated rats with ethanol, chloroform, petroleum-ether extracts, and silymarin showed normal appearance of tubules, glomeruli, and tubulointerstitial cells (Figures 4(a), 4(b), 4(c), 4(d), and $4(\mathrm{e})$, resp.). Collagen deposition was of normal range in all control groups (Figures 5(a), 5(b), 5(c), 5(d), and 5(e), resp.).
Kidney section of $\mathrm{CCl}_{4}$-treated rats showed glomerular and tubular degenerations varying from glomerular basement membrane thickening, mild dilatation or congestion of space of Bowman, interstitial inflammation, tubular cell swelling or congestion, tubular brush border loss, tubular dilatation, and necrosis of epithelium to interstitial oedema (Figure 6(a)). Marked collagen deposition was recorded $(60.2 \%$, Figure $7(a))$.

Ozturk et al. [44] recorded similar histopathological alterations in rats kidney treated with $\mathrm{CCl}_{4}$ characterized by tubular epithelial cells alterations including vacuolization, atrophy, detachment of epithelial cells, and tubular necrosis. With these histopathological changes, the capacity of tubular absorption may have been altered and functional overloading of nephrons with subsequent renal dysfunction was observed [3]. 


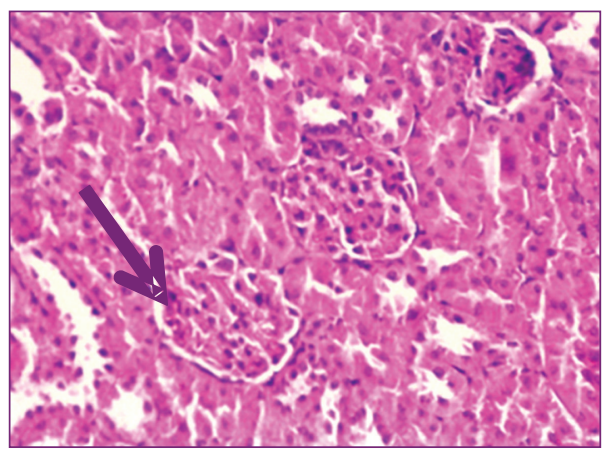

(a)

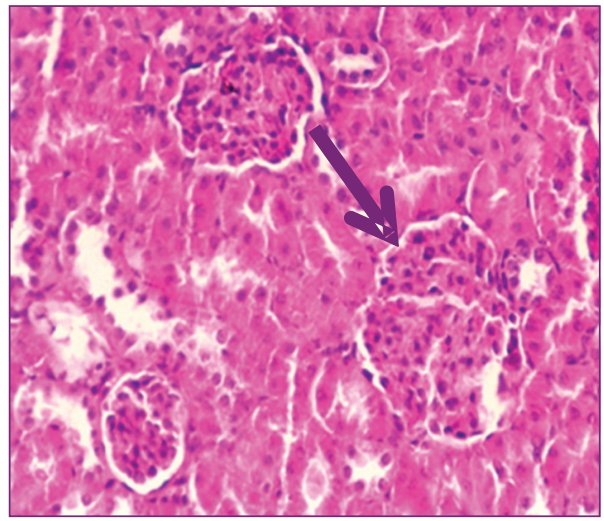

(c)

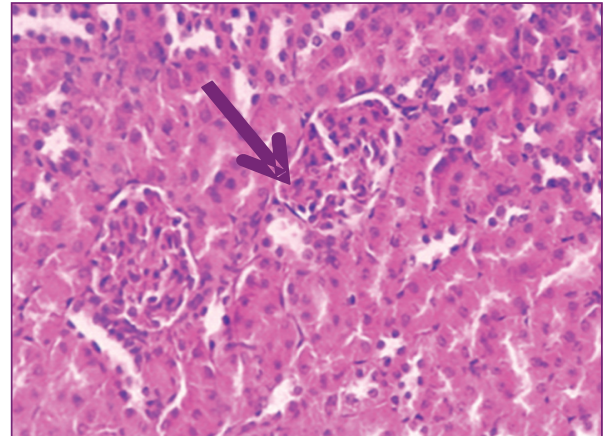

(b)

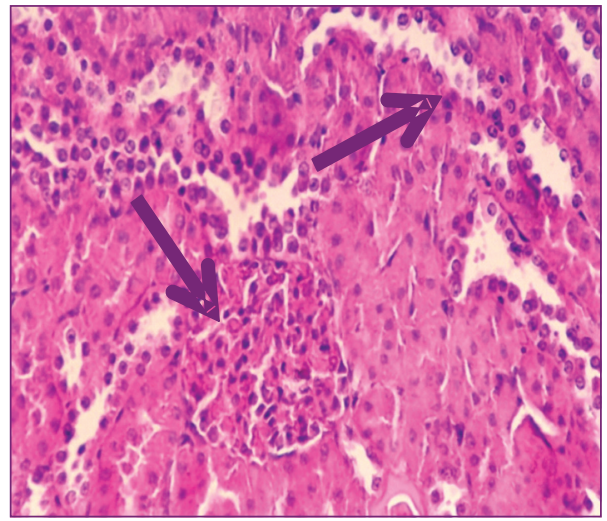

(d)

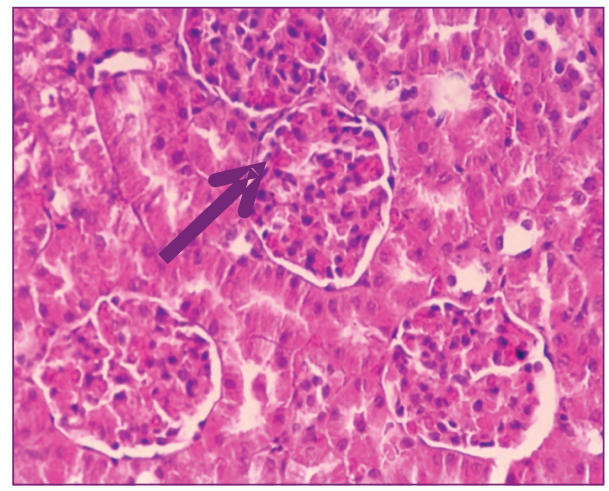

(e)

Figure 4: Photomicrography of kidney sections (200x) of control (a), control treated with ethanol extract (b), control treated with chloroform extract (c), control treated with petroleum ether extract (d), and control treated with silymarin (e) stained with haematoxylin and eosin.

Carbon tetrachloride group treated with ethanol extract of ginger showed almost normal morphology and normal architecture of the kidney (Figure 6(b)). Glomeruli and tubules appeared to be regenerated following chloroform extract (Figure 6(c)). Group of $\mathrm{CCl}_{4}$ treated with petroleum ether extract showed normal morphology with the exception of only few swollen glomeruli and rare vascular congestions that were present in both cortical and corticomedullar regions (Figure 6(d)). Kidney section of $\mathrm{CCl}_{4}$ treated with silymarin revealed regeneration of renal cells and regeneration of tubules nearly as seen in control group (Figure 6(e)). In all treated groups, neither interstitial inflammatory cell infiltrations nor an increase in the connective tissue cells was observed. Mild collagen deposition in ethanoland chloroform-treated groups was observed (17.00 and $23.20 \%$, resp.; Figures 7 (b) and $7(\mathrm{c})$ ), while moderated 


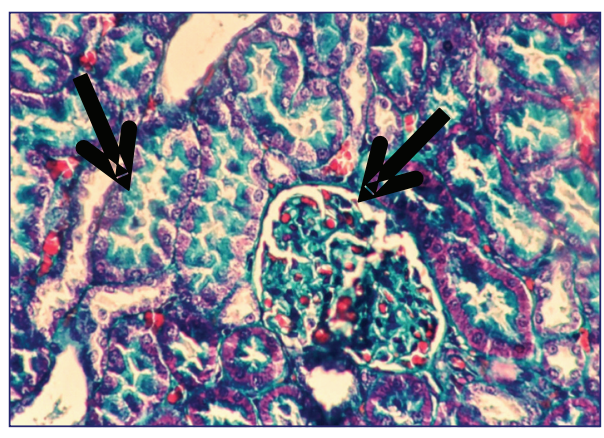

(a)

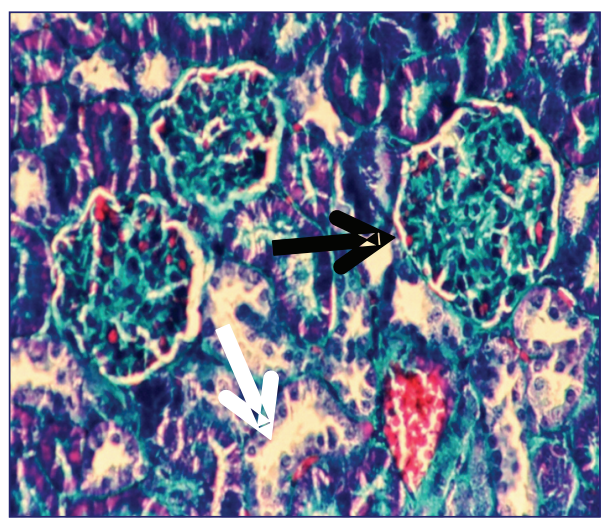

(c)

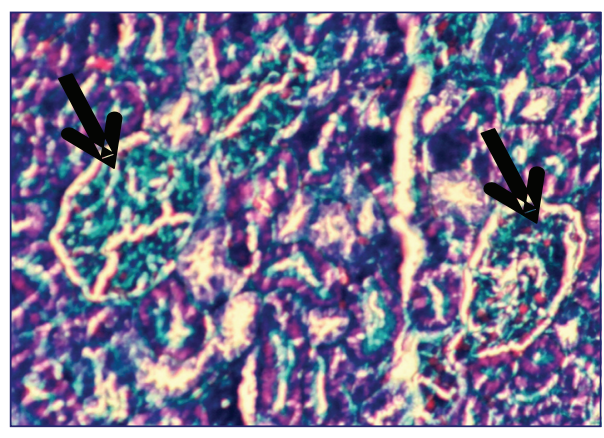

(b)

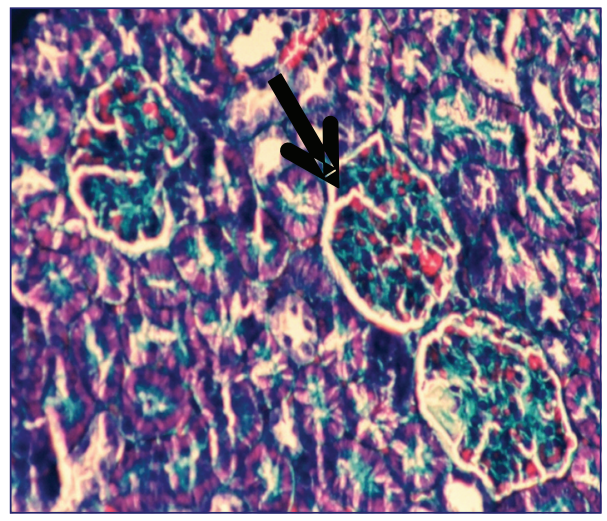

(d)

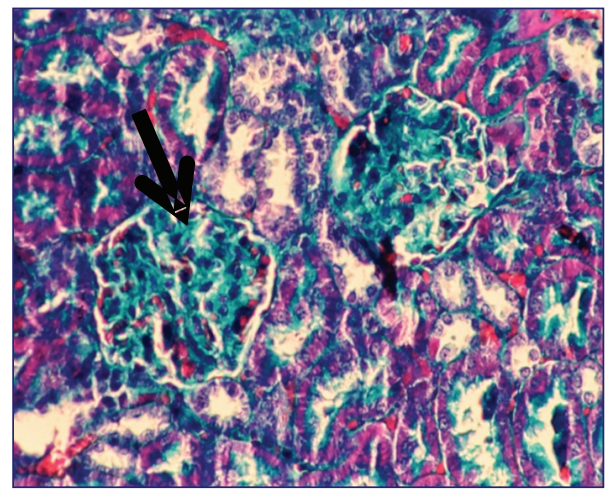

(e)

FIGURE 5: Photomicrography of kidney sections (200x) of control (a), control treated with ethanol extract (b), control treated with chloroform extract (c), control treated with petroleum ether extract (d), and control treated with silymarin (e) stained with Masson's trichrome.

deposition was recorded after treatment with petroleum ether extract and silymarin of 27.60 and $30.80 \%$, respectively (Figures $7(\mathrm{~d})$ and $7(\mathrm{e}))$. The histopathological changes were graded and summarized in Table 1.

The corrective histopathological findings after treatment with ginger extracts give an additional support that ginger mops up free radicals generation by $\mathrm{CCl}_{4}$, reduces inflammation, improves kidney function, and induces healthy state of renal cells, suggesting its role as renal protective agent. This was attributed to their abundance of natural antioxidants: flavonoids, sterols, and alkaloids. Also, silymarin, as an antioxidant flavonoid complex derived from the herb milk thistle (Silybum marianum), has the ability to scavenge free radicals, chelate metal ions, and inhibit lipid peroxidation [44]. In parallel with our results, ginger recorded a promise role against renal ischemia [45], renal damage induced by alcohol intoxication [46], and renal toxicity induced by doxorubicin, the commonly used anticancer drug [47]. 


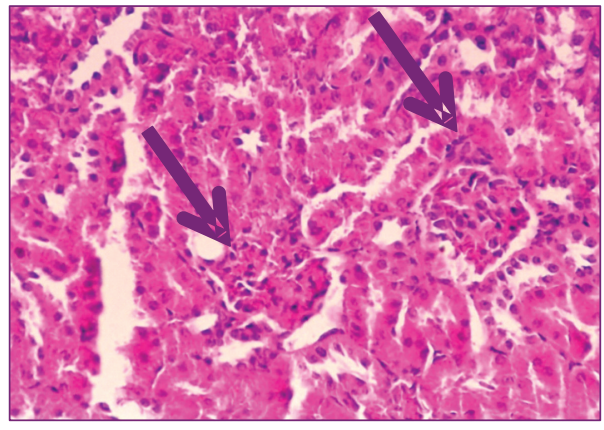

(a)

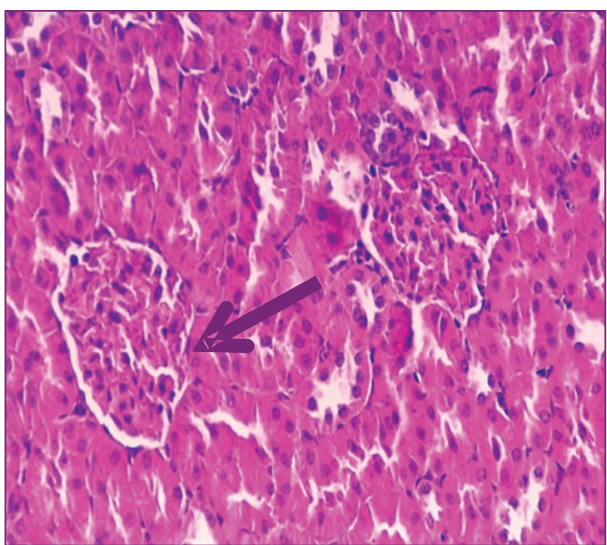

(c)

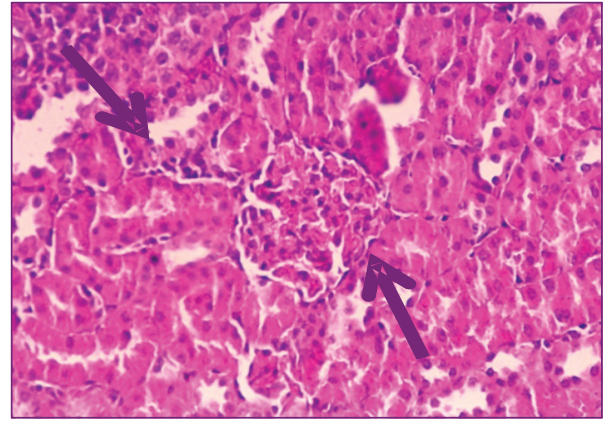

(b)

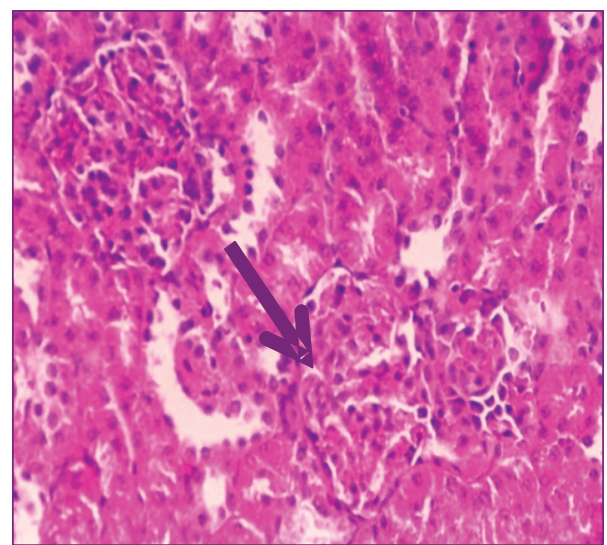

(d)

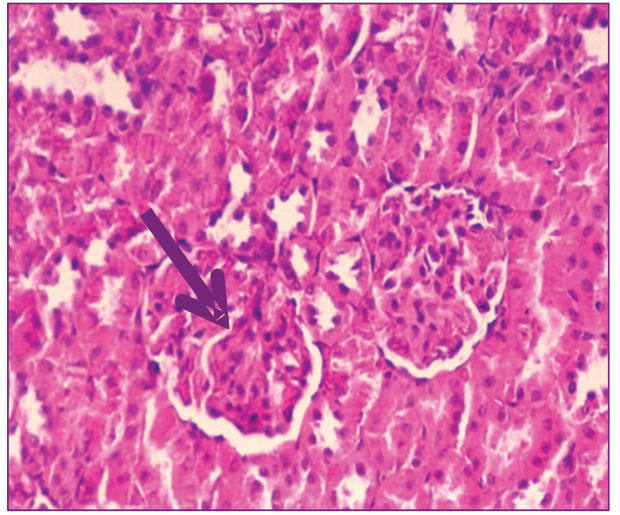

(e)

FigURE 6: Photomicrography of kidney sections (200x) of $\mathrm{CCl}_{4}$ (a), $\mathrm{CCl}_{4}$ treated with ethanol extract (b), $\mathrm{CCl}_{4}$ treated with chloroform extract (c), $\mathrm{CCl}_{4}$ treated with petroleum ether extract (d), and $\mathrm{CCl}_{4}$ treated with silymarin (e) stained with haematoxylin and eosin.

TABLE 1: Effect of petroleum ether, chloroform, ethanol extracts, and silymarin drug treatment on histopathological examination of rats kidney exposed to $\mathrm{CCl}_{4}$.

\begin{tabular}{|c|c|c|c|c|c|}
\hline Groups & $\begin{array}{c}\text { Tubular cell } \\
\text { swelling }\end{array}$ & $\begin{array}{c}\text { Interstitial } \\
\text { inflammation }\end{array}$ & $\begin{array}{c}\text { Tubular } \\
\text { dilatation }\end{array}$ & $\begin{array}{l}\text { Necrosis of } \\
\text { epithelium }\end{array}$ & $\begin{array}{c}\text { Glomerular } \\
\text { Hypercellularity }\end{array}$ \\
\hline Control & - & - & - & - & - \\
\hline $\mathrm{CCL}_{4}$ & +++ & +++ & +++ & +++ & +++ \\
\hline $\mathrm{CCl}_{4}+$ ethanol extract & - & - & - & - & - \\
\hline $\mathrm{CCl}_{4}+$ chloroform extract & $+/-$ & $+1-$ & - & - & $+/-$ \\
\hline $\mathrm{CCl}_{4}+$ petroleum-ether extract & $+1-$ & ++ & $+1-$ & $+1-$ & + \\
\hline $\mathrm{CCl}_{4}+$ sylimarin drug & - & - & - & - & - \\
\hline
\end{tabular}

Severity of renal histological changes using scores on a scale of none (-), mild (+), moderate $(++)$, and severe (+++) damage. 


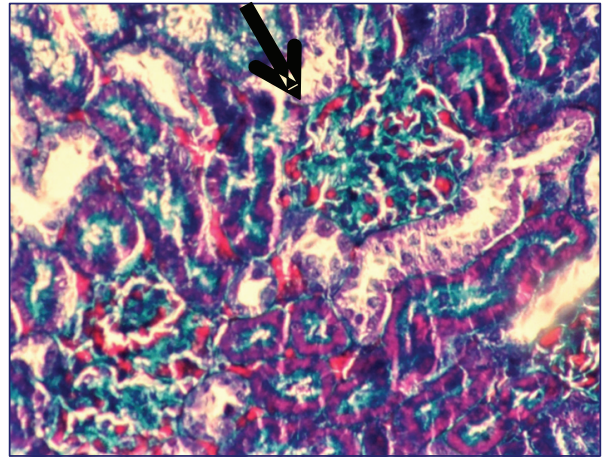

(a)

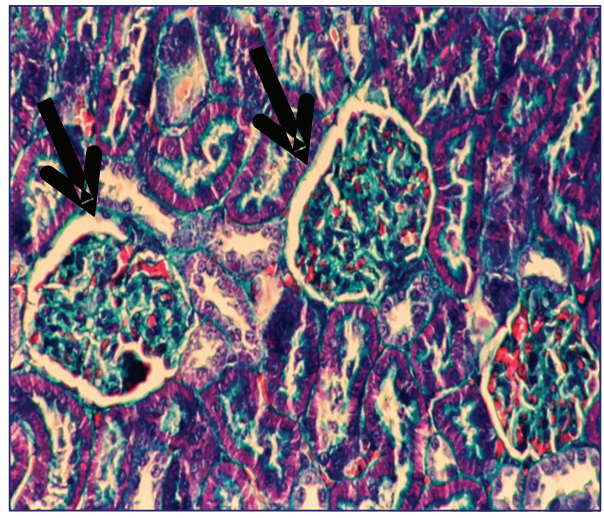

(c)

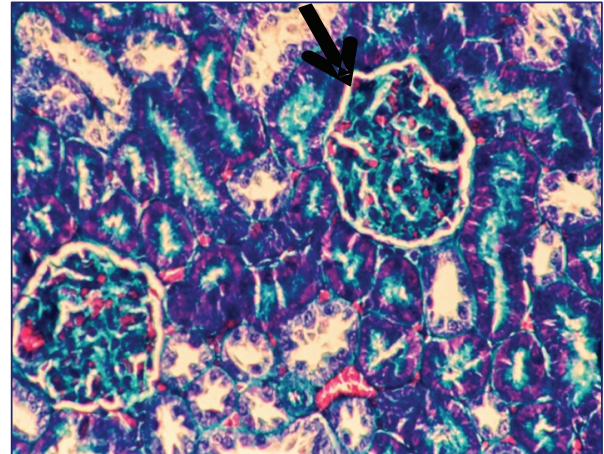

(b)

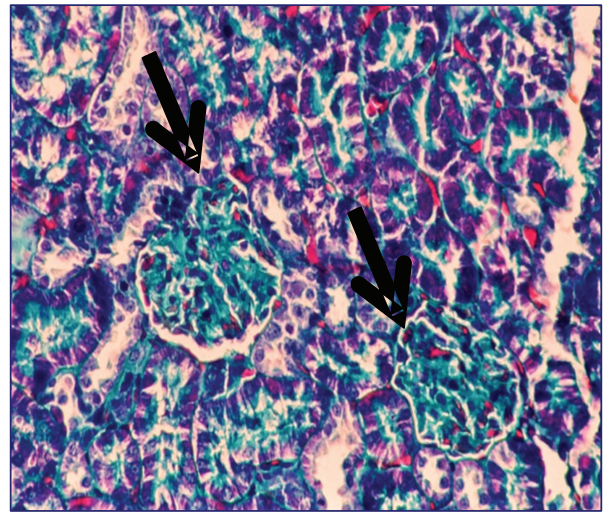

(d)

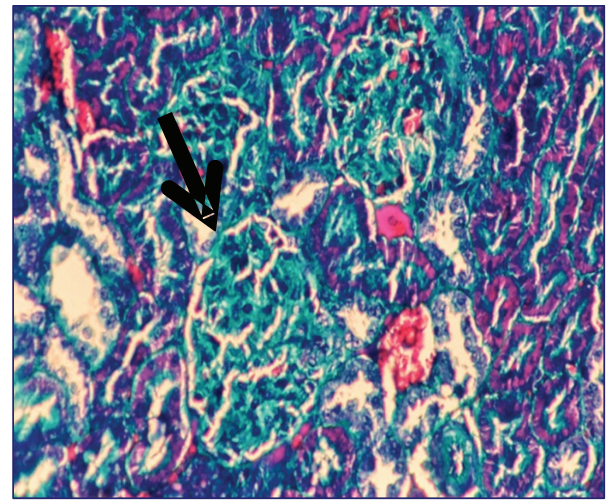

(e)

FIGURE 7: Photomicrography of kidney sections (200x) of $\mathrm{CCl}_{4}(\mathrm{a}), \mathrm{CCl}_{4}$ treated with ethanol extract (b), $\mathrm{CCl}_{4}$ treated with chloroform extract (c), $\mathrm{CCl}_{4}$ treated with petroleum ether extract (d), and $\mathrm{CCl}_{4}$ treated with silymarin (e) stained with Masson's trichrome.

\section{Conclusions}

$\mathrm{CCl}_{4}$-induced nephrotoxicity by free radicals involvement impaired renal functions, altered antioxidant levels, enhanced inflammation and fibrosis, affecting harmfully the kidney functionality. Ginger provides evidence for kidney protection and reduces severity of damage induced by $\mathrm{CCl}_{4}$ intoxication. Ethanol extract recorded the most potent effect due to its content of flavonoids, sterols, triterpenes, carbohydrate, and alkaloids. However, further detailed studies are required to establish its clinical application and to identify the molecules responsible of the pharmacological activity.

\section{Conflict Interests}

The authors declare no conflict of interests. 


\section{Acknowledgment}

The authors would like to thank Dr. Manal Hassen Shabana, Phytochemistry and Plant Systematic Department, National Research Center, Cairo, Egypt, for preparing the extracts.

\section{References}

[1] M. Cabré, J. Camps, Jl. Paternáin, N. Ferré, and J. Joven, "Time-course of changes in hepatic lipid peroxidation and glutathione metabolism in rats with carbon tetrachlorideinduced cirrhosis," Clinical and Experimental Pharmacology and Physiology, vol. 27, no. 9, pp. 694-699, 2000.

[2] T. Jayakumar, M. Sakthivel, P. A. Thomas, and P. Geraldine, "Pleurotus ostreatus, an oyster mushroom, decreases the oxidative stress induced by carbon tetrachloride in rat kidneys, heart and brain," Chemico-Biological Interactions, vol. 176, no. 2-3, pp. 108-120, 2008.

[3] M. R. Khan, W. Rizvi, G. N. Khan, R. A. Khan, and S. Shaheen, "Carbon tetrachloride-induced nephrotoxicity in rats: protective role of Digera muricata," Journal of Ethnopharmacology, vol. 122, no. 1, pp. 91-99, 2009.

[4] R. A. Khan, M. R. Khan, S. Sahreen, and J. Bokhari, "Prevention of CCl4-induced nephrotoxicity with Sonchus asper in rat," Food and Chemical Toxicology, vol. 48, no. 8-9, pp. 2469-2476, 2010.

[5] S. K. Natarajan, J. Basivireddy, A. Ramachandran et al., "Renal damage in experimentally-induced cirrhosis in rats: role off oxygen free radicals," Hepatology, vol. 43, no. 6, pp. 12481256, 2006.

[6] J.-P. Pradère, J. Gonzalez, J. Klein et al., "Lysophosphatidic acid and renal fibrosis," Biochimica et Biophysica Acta, vol. 1781, no. 9, pp. 582-587, 2008.

[7] M. A. Al-Bayati, Y. Xie, F. C. Mohr, S. B. Margolin, and S. N. Giri, "Effect of pirfenidone against vanadate-induced kidney fibrosis in rats," Biochemical Pharmacology, vol. 64, no. 3, pp. 517-525, 2002.

[8] E. P. Cohen, "Fibrosis causes progressive kidney failure," Medical Hypotheses, vol. 45, no. 5, pp. 459-462, 1995.

[9] M. G. Rajesh and M. S. Latha, "Protective activity of Glycyrrhiza glabra Linn. on carbon tetrachloride-induced peroxidative damage," Indian Journal of Pharmacology, vol. 36, no. 5, pp. 284-287, 2004.

[10] S. O. Adewole, A. A. Salako, O. W. Doherty, and T. Naicker, "Effect of melatonin on carbon tetrachloride-induced kidney injury in Wistar rats," African Journal of Biomedical Research, vol. 10, pp. 153-164, 2007.

[11] A. A. Shati and F. G. Elsaid, "Effects of water extracts of thyme (Thymus vulgaris) and ginger (Zingiber officinale Roscoe) on alcohol abuse," Food and Chemical Toxicology, vol. 47, no. 8, pp. 1945-1949, 2009.

[12] A. S. El-Sharaky, A. A. Newairy, M. A. Kamel, and S. M. Eweda, "Protective effect of ginger extract against bromobenzeneinduced hepatotoxicity in male rats," Food and Chemical Toxicology, vol. 47, no. 7, pp. 1584-1590, 2009.

[13] M. S. Islam and H. Choi, "Comparative effects of dietary ginger (Zingiber officinale) and garlic (Allium sativum) investigated in a type 2 diabetes model of rats," Journal of Medicinal Food, vol. 11, no. 1, pp. 152-159, 2008.

[14] A. Matsuda, Z. Wang, S. Takahashi, T. Tokuda, N. Miura, and J. Hasegawa, "Upregulation of mRNA of retinoid binding protein and fatty acid binding protein by cholesterol enricheddiet and effect of ginger on lipid metabolism," Life Sciences, vol. 84, no. 25-26, pp. 903-907, 2009.

[15] S. H. M. Habib, S. Makpol, N. A. A. Hamid, S. Das, W. Z. W. Ngah, and Y. A. M. Yusof, "Ginger extract (Zingiber officinale) has anti-cancer and anti-inflammatory effects on ethionineinduced hepatoma rats," Clinics, vol. 63, no. 6, pp. 807-813, 2008.

[16] F. Sharififar, M. H. Moshafi, G. Dehghan-Nudehe, A. Ameri, F. Alishahi, and A. Pourhemati, "Bioassay screening of the essential oil and various extracts from 4 spices medicinal plants," Pakistan Journal of Pharmaceutical Sciences, vol. 22, no. 3, pp. 317-322, 2009.

[17] N. G. Martinez Nadal, "Sterols of Spirulina maxima," Phytochemistry, vol. 10, no. 10, pp. 2537-2538, 1971.

[18] M. K. Seikel, "Chromatographic methods of separation, isolation and identification of flavonoid compounds," in The Chemistry of Flavonoid Compounds, pp. 34-69, Macmillan, New York, NY, USA, 1962.

[19] G. E. Trease and M. C. Evans, in Trease and Evans Pharmacognosy, pp. 343-383, BallieveTindal, London, UK, 12 edition, 2003.

[20] J. Marsillach, J. Camps, N. Ferré et al., "Paraoxonase-1 is related to inflammation, fibrosis and PPAR delta in experimental liver disease," BMC Gastroenterology, vol. 9, article 3, 2009.

[21] P. Yuvaraj and A. Subramoniam, "Hepatoprotective property of Thespesia populnea against carbon tetrachloride induced liver damage in rats," Journal of Basic and Clinical Physiology and Pharmacology, vol. 20, no. 2, pp. 169-177, 2009.

[22] J. A. Buege and S. D. Aust, "Microsomal lipid peroxidation," Methods in Enzymology, vol. 52, pp. 302-310, 1978.

[23] M. S. Moron, J. W. Depierre, and B. Mannervik, "Levels of glutathione, glutathione reductase and glutathione Stransferase activities in rat lung and liver," Biochimica et Biophysica Acta, vol. 582, no. 1, pp. 67-78, 1979.

[24] M. Nishikimi, N. A. Rae, and K. Yagi, "The occurrence of superoxide anion in the action of reduced phenazine methosulphate and molecular oxygen," Biochemical and Biophysical Research Communications, vol. 46, pp. 849-853, 1972.

[25] A. Tabacco, F. Meiattini, E. Moda, and P. Tarli, "Simplified enzymic/colorimetric serum urea nitrogen determination," Clinical Chemistry, vol. 25, no. 2, pp. 336-337, 1979.

[26] H. Bartels and M. Böhmer, "Eine mikromethode zur kreatininbestimmung," Clinica Chimica Acta, vol. 32, no. 1, pp. 8185, 1971.

[27] M. M. Bradford, "A rapid and sensitive method for the quantitation of microgram quantities of protein utilizing the principle of protein dye binding," Analytical Biochemistry, vol. 72, no. 1-2, pp. 248-254, 1976.

[28] M. Hamberg and B. Samuelsson, "On the metabolism of prostaglandins $\mathrm{E}_{1}$ and $\mathrm{E}_{2}$ in man," Journal of Biological Chemistry, vol. 246, no. 22, pp. 6713-6721, 1971.

[29] H. Suzuki and K. Suzuki, "Rat hypoplastic kidney $(h p k / h p k)$ induces renal anemia, hyperparathyroidism, and osteodystrophy at the end stage of renal failure," Journal of Veterinary Medical Science, vol. 60, no. 10, pp. 1051-1058, 1998.

[30] T. K. Motawi, M. A. Hamed, M. H. Shabana, R. M. Hashem, and A. F. Aboul Naser, "Zingiber officinale acts as a nutraceutical agent against liver fibrosis," Nutrition and Metabolism, vol. 8, article 40, 2011.

[31] C. A. Anosike, O. Obidoa, L. U. S. Ezeanyika, and M. M. Nwuba, "Anti-inflammatory and anti-ulcerogenic activity of 
the ethanol extract of ginger (Zingiber officinale)," African Journal of Biochemistry Research, vol. 3, pp. 379-384, 2009.

[32] S. A. Sheweita, M. Abd El-Gabar, and M. Bastawy, "Carbon tetrachloride changes the activity of cytochrome P450 system in the liver of male rats: role of antioxidants," Toxicology, vol. 169, no. 2, pp. 83-92, 2001.

[33] M. R. Khan and D. Ahmed, "Protective effects of Digera muricata (L.) Mart. on testis against oxidative stress of carbon tetrachloride in rat," Food and Chemical Toxicology, vol. 47, no. 6, pp. 1393-1399, 2009.

[34] R. Smyth, J. A. Turton, C. J. Clarke et al., "Identification of superoxide dismutase as a potential urinary marker of carbon tetrachloride-induced hepatic toxicity," Food and Chemical Toxicology, vol. 46, no. 9, pp. 2972-2983, 2008.

[35] I. Stoilova, A. Krastanov, A. Stoyanova, P. Denev, and S. Gargova, "Antioxidant activity of a ginger extract (Zingiber officinale)," Food Chemistry, vol. 102, no. 3, pp. 764-770, 2007.

[36] M. Ogeturk, I. Kus, N. Colakoglu, I. Zararsiz, N. Ilhan, and M. Sarsilmaz, "Caffeic acid phenethyl ester protects kidneys against carbon tetrachloride toxicity in rats," Journal of Ethnopharmacology, vol. 97, no. 2, pp. 273-280, 2005.

[37] M. Mehrdad, M. Messripour, and M. Ghobadipour, "The effect of ginger extract on blood urea nitrogen and creatinine in mice," Pakistan Journal of Biological Sciences, vol. 10, no. 17, pp. 2968-2971, 2007.

[38] L. Choi, M. Y. Kwak, E. H. Kwak et al., "Comparative nephrotoxicitiy induced by melamine, cyanuric acid, or a mixture of both chemicals in either Sprague-Dawley rats or renal cell lines," Journal of Toxicology and Environmental Health, Part A, vol. 73, no. 21-22, pp. 1407-1419, 2010.

[39] I. Carlsen, K. E. Donohue, A. M. Jensen et al., "Increased cyclooxygenase- 2 expression and prostaglandin $\mathrm{E}_{2}$ production in pressurized renal medullary interstitial cells," American Journal of Physiology, vol. 299, no. 3, pp. R823-R831, 2010.

[40] R. Nørregaard, B. L. Jensen, S. O. Topcu et al., "Urinary tract obstruction induces transient accumulation of COX-2-derived prostanoids in kidney tissue," American Journal of Physiology, vol. 298, no. 4, pp. R1017-R1025, 2010.

[41] C. L. Hsu, B. O. H. Hong, Y. U. Shan, and G. C. Yen, "Antioxidant and anti-inflammatory effects of Orthosiphon aristatus and its bioactive compounds," Journal of Agricultural and Food Chemistry, vol. 58, no. 4, pp. 2150-2156, 2010.

[42] S. R. Khubchandani, A. R. Chitale, and S. Gowrishankar, "Banded collagen in the kidney with special reference to collagenofibrotic glomerulopathy," Ultrastructural Pathology, vol. 34, no. 2, pp. 68-72, 2010.

[43] M. A. Haralson, S. J. Dimari, R. L. Hoover, and R. C. Harris, "Effects of epidermal growth factor on collagen expression by rat kidney mesangial cells in culture," Matrix Biology, vol. 19, no. 1, pp. 47-59, 2000.

[44] F. Ozturk, M. Ucar, I. C. Ozturk, N. Vardi, and K. Batcioglu, "Carbon tetrachloride-induced nephrotoxicity and protective effect of betaine in Sprague-Dawley rats," Urology, vol. 62, no. 2, pp. 353-356, 2003.

[45] S. Maghsoudi, A. Gol, S. Dabiri, and A. Javadi, "Preventive effect of ginger (Zingiber officinale) pretreatment on renal ischemia-reperfusion in rats," European Surgical Research, vol. 46, no. 1, pp. 45-51, 2010.

[46] K. R. Shanmugam, C. H. Ramakrishna, K. Mallikarjuna, and K. S. Reddy, "Protective effect of ginger against alcoholinduced renal damage and antioxidant enzymes in male albino rats," Indian Journal of Experimental Biology, vol. 48, no. 2, pp. 143-149, 2010.
[47] T. A. Ajith, M. S. Aswathy, and U. Hema, "Protective effect of Zingiber officinale roscoe against anticancer drug doxorubicininduced acute nephrotoxicity," Food and Chemical Toxicology, vol. 46, no. 9, pp. 3178-3181, 2008. 

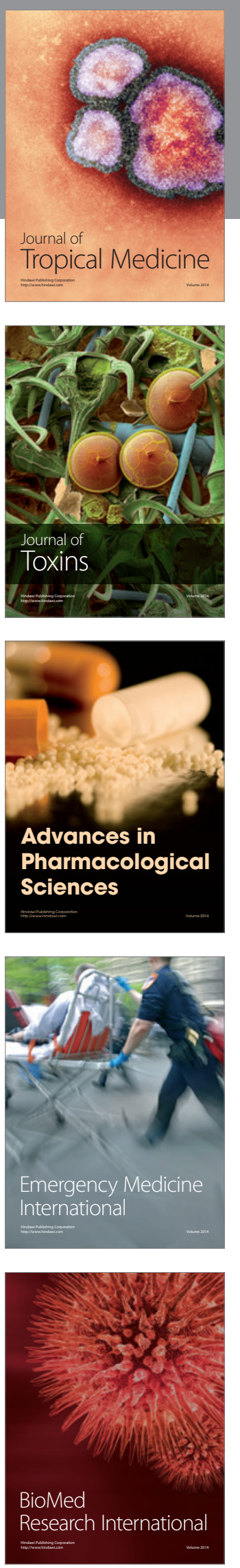
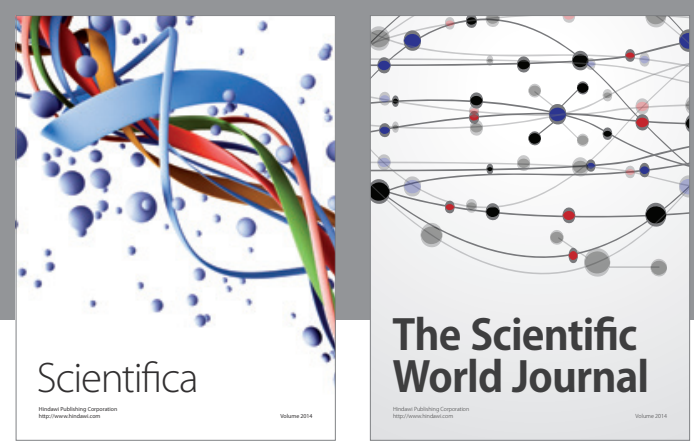

The Scientific World Journal
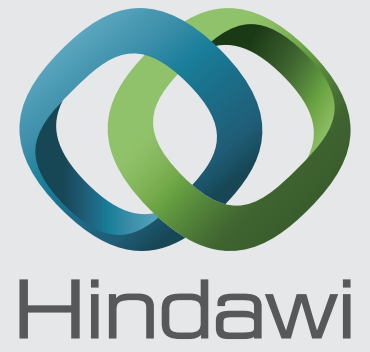

Submit your manuscripts at

http://www.hindawi.com
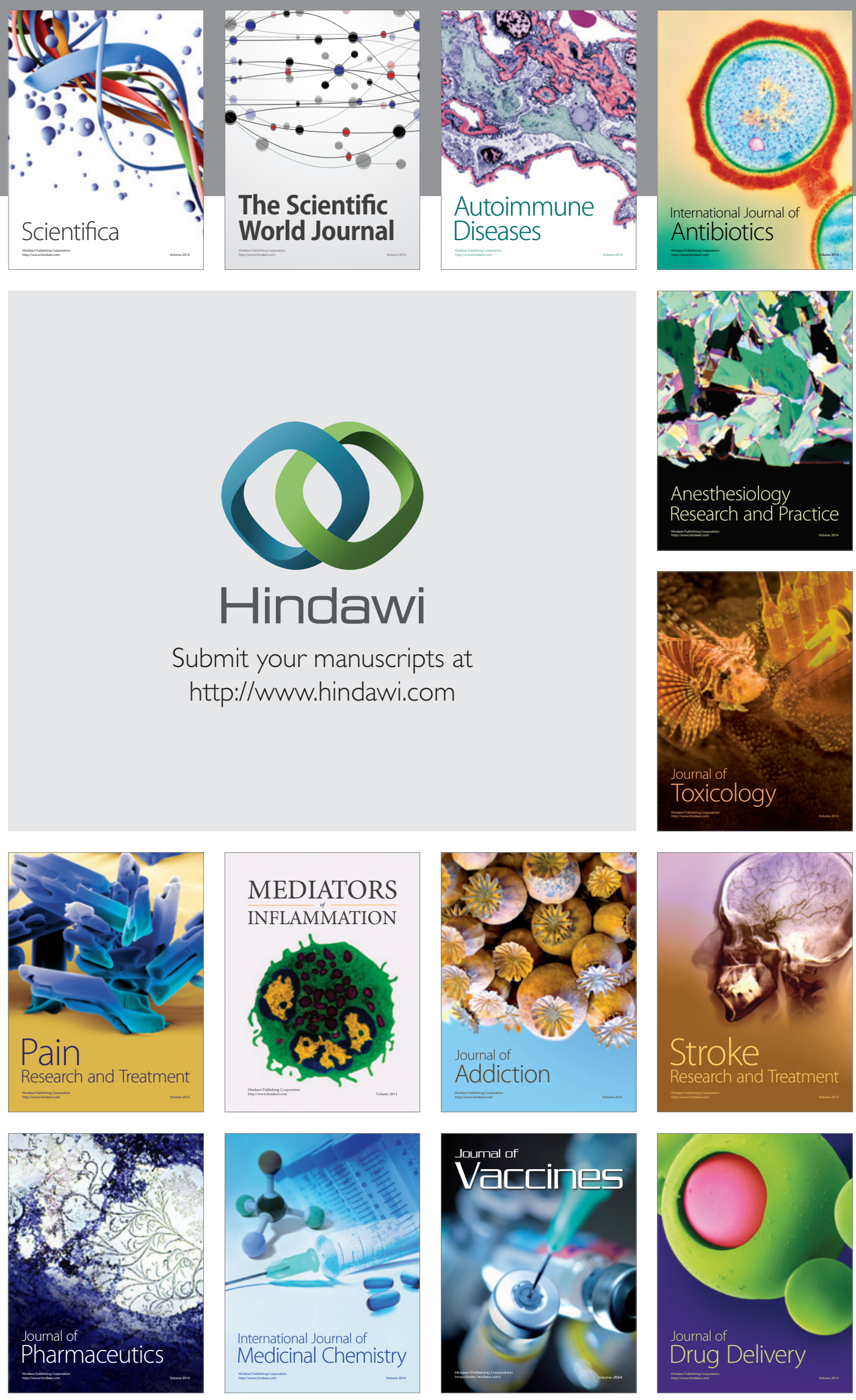